\title{
Adsorption of Lead, manganese, and copper onto biochar in landfill leachate: implication of non-linear regression analysis
}

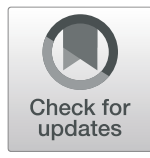

\author{
Ali Daryabeigi Zand ${ }^{*}$ and Maryam Rabiee Abyaneh
}

\begin{abstract}
The feasibility of using wood-derived biochar (BC) to remove $\mathrm{Pb}, \mathrm{Mn}$, and $\mathrm{Cu}$ from landfill leachate was investigated and modeled in this study. $\mathrm{BC}$ was produced under the pyrolytic temperature of $740^{\circ} \mathrm{C}$. The effect of contact time, $\mathrm{BC}$ dosage and particle size on adsorption of the heavy metals onto BC was examined. BC was used in two forms i.e., pulverized (PWB) and crushed (CWB) to evaluate the effect of BC particle size on adsorption characteristics. The kinetics of $\mathrm{Pb}, \mathrm{Mn}$, and $\mathrm{Cu}$ adsorption onto PWB and CWB were assessed using the pseudo second-order and Elovich models, where both applied models could well describe the adsorption kinetics. Removal efficiencies of the heavy metals were increases by 1.2, 1.4, and 1.6 times, respectively, for Pb, Mn, and $\mathrm{Cu}$, when PWB content of the leachate increased from 0.5 to $5 \mathrm{~g} \mathrm{~L}^{-1}$. Equilibrium adsorption capacity of the heavy metals onto $B C$ in leachate system was evaluated using the Langmuir, non-linearized Freundlich, linearized Freundlich, and Temkin isotherms and found to have the following order for PWB: Non-linearized Freundlich > Temkin > Langmuir > Linearized Freundlich. The Langmuir and linearized Freundlich models could not adequately represent adsorption of the heavy metals onto BC, especially for CWB. The highest removal of $88 \%$ was obtained for $\mathrm{Pb}$, while the greatest adsorption intensity was found to be $1.58 \mathrm{mg} \mathrm{g}^{-1}$ for $\mathrm{Mn}$. Using the non-linearized Freundlich isotherm significantly reduced adsorption prediction error. The adsorption affinity of PWB for Pb, Mn, and Cu was greater than that of CWB in all treatments. Wood-derived BC is suggested to be used for the removal of heavy metals from landfill leachate as an economical adsorbent.
\end{abstract}

Keywords: Adsorption, Biochar, Landfill leachate, Heavy metals, Linearization error

\section{Introduction}

Landfill leachate may contain a wide range of contaminants at levels enough to raise serious environmental and human health concerns. The majority of published research has focused on removal of ammonia and organic fraction of landfill leachates, such as using biological reactors [1], oxidation processes [2] and membrane separation [3]. Concentrations of heavy metals in fresh landfill leachate, characterized by lower $\mathrm{pH}$, are usually higher than those in aged leachate [4]. Adsorption of heavy metals on carbonaceous materials has received considerable attention to remove toxic metals from contaminated aqueous

\footnotetext{
* Correspondence: adzand@ut.ac.ir
School of Environment, College of Engineering, University of Tehran, Tehran

* Correspondence: adzand@ut.ac.ir
School of Environment, College of Engineering, University of Tehran, Tehran 141556135, Iran

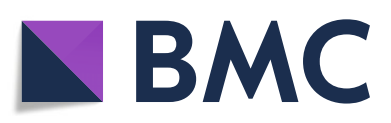

(๑) The Author(s). 2020 Open Access This article is licensed under a Creative Commons Attribution 4.0 International License, which permits use, sharing, adaptation, distribution and reproduction in any medium or format, as long as you give

appropriate credit to the original author(s) and the source, provide a link to the Creative Commons licence, and indicate if changes were made. The images or other third party material in this article are included in the article's Creative Commons licence, unless indicated otherwise in a credit line to the material. If material is not included in the article's Creative Commons licence and your intended use is not permitted by statutory regulation or exceeds the permitted use, you will need to obtain permission directly from the copyright holder. To view a copy of this licence, visit http://creativecommons.org/licenses/by/4.0/. from a synthetically contaminated aqueous solution [11].
} from synthetic aqueous solution by adsorption onto carbon nanotubes through a set of batch experiments which showed effective removal of heavy metals [5]. Activated carbon $(\mathrm{AC})$ is a well-known strong adsorbent which has been employed to remove heavy metals from different media principally because of its large surface area and high porosity [6-8]. Palm shell AC was successfully used to remove $\mathrm{Cu}$ from aqueous solution [9]; but high production expenses of AC may limit its use as adsorbent [10]. Application of economical alternatives to $\mathrm{AC}$ has therefore drawn remarkable attention in recent years. For instance, in a study by Soco and Kalembkiewicz, coal fly ash was successfully used for the removal of nickel and copper 
Adsorption process rate is usually studied using kinetic models, while the variation in the amount of sorbate adsorbed by different doses of adsorbent is evaluated by isotherm models, which is critical in optimizing the use of adsorbents. Various models have been proposed to study adsorption of heavy metals onto carbonous materials in aqueous solutions [12-14]. The adsorption kinetics of $\mathrm{Pb}$ and $\mathrm{Zn}$ onto carbon nanotubes in aqueous solutions were described well using pseudo-second-order and Elovich models. Lagergren pseudo-first-order model was not able to predict adsorption kinetics of the metals as precise as pseudo-second-order and Elovich models [5]. The applicability of the pseudo-second-order and Elovich models to predict adsorption kinetics of heavy metals in contaminated aqueous solutions has been reported in the literature [15-17]. Temkin isotherm model assumes that the heat of adsorption of all the molecules in layer declines as adsorbent surface coverage increases due to adsorbateadsorbate repulsions. Fall in the heat of adsorption is considered to be linear for Temkin isotherm rather than logarithmic. Adsorption of adsorbate onto adsorbent is also characterized by a unisonous distribution of binding energies up to ca. maximum binding energy [14]. Adsorption of chlorophenoxyacetic acid herbicides from water onto orange peel AC was successfully described by Temkin isotherm model [18]. Moreover, the Temkin model could satisfactory predict adsorption of $\mathrm{Cr}(\mathrm{VI})$ onto $\mathrm{AC}$, though higher $R^{2}$ values were found using the Freundlich and Langmuir equations [19]. Freundlich and Langmuir equations are the most well-known models for describing adsorption isotherm [20]; but applying non-linearized form of the Freundlich model in adsorption studies has been scant. Isotherm and kinetic models are often applied in linear form, though linearization of the original model might violate the theories and assumptions behind the development of a given model. That means when model parameters are estimated based on linear transformation it would not necessarily yield the best fitting parameters for the nonlinear original model [21]. Error analysis for the kinetic and isotherm models, which has rarely been studied in adsorption of heavy metals onto biochar (BC) in landfill leachate, was also investigated in this paper.

Recently, use of $\mathrm{BC}$ has attracted considerable attention [22]. de Caprariis et al. employed BC to remove total organic carbon from wastewater, and a very high sorption capacity of BC $\left(840 \mathrm{mg} \mathrm{g}^{-1}\right)$ was achieved [23]. In another study, $\mathrm{BC}$ derived from sewage sludge eliminated $\mathrm{Cr}$ from water significantly by $89 \%$, whereas As removal did not exceed 53\% [24]. Many studies have focused on the immobilization and mitigation of contaminants, respectively, in soil and effluents $[25,26]$; however, removal of heavy metals from landfill leachate by $\mathrm{BC}$ has rarely been investigated. This research aimed to investigate the adsorption of $\mathrm{Pb}, \mathrm{Mn}$ and $\mathrm{Cu}$ onto wood-derived $\mathrm{BC}$ in fresh landfill leachate. We specifically studied: (i) effect of contact time, BC dosage and particle size on adsorption of heavy metals onto $\mathrm{BC}$; (ii) adsorption kinetics of the heavy metals onto $\mathrm{BC}$ in landfill leachate using pseudo secondorder and Elovich models; and (iii) modeling of adsorption of the heavy metals onto $\mathrm{BC}$ in landfill leachate using Freundlich (linearized and non-linearized), Langmuir and Temkin isotherms.

\section{Materials and methods}

\section{Site description and leachate sampling and analysis}

Kahrizak landfill which is also known as Aradkooh waste disposal and processing complex is main disposal site of the capital city of Tehran, located at a $25 \mathrm{~km}$ distance from the southern part of the capital city of Tehran having longitude of $51^{\circ} 19^{\prime} 18^{\prime \prime} \mathrm{E}$ and latitude of $35^{\circ} 27^{\prime} 52^{\prime \prime} \mathrm{N}$. More than $8 \mathrm{kt}$ of wastes are transferred daily to the landfill site. Household hazardous wastes are buried together with general wastes. Generated leachate at Kahrizak landfill is a serious environmental and health threat. High clay content and therefore low permeability of the land around the landfill caused infiltration of the landfill leachate to be minimal. Therefore, freshly generated leachate at Kahrizak landfill, which is now estimated to be about $637 \mathrm{~m}^{3} \mathrm{~d}^{-1}$ [27], flows gravitationally towards the low land next to the burial site creating a leachate lake with a depth of ca. $10 \mathrm{~m}$, with seasonal variations. In this study, the leachate samples were directly collected from the generated leachate stream at the bottom of the waste discharge place at Kahrizak landfill and used for the adsorption experiments. Overflow of the fresh leachate from newly-filled trenches was directly collected in four 10-L plastic containers. Collected leachate can be classified as relatively fresh leachate based on the low $\mathrm{pH}$ values (5.11). Leachate samples were immediately transported to the laboratory. Samples were kept refrigerated at $4{ }^{\circ} \mathrm{C}$ without exposure to the ambient air for not more than 3 days before conducting relevant analysis to prevent potential chemical and biological changes.

Leachate samples characterized according to the Standard Methods for the Examination of Water and Wastewater [28]. Raw samples were filtered using Whatman Paper Filter No. 1 (pore size: $11 \mu \mathrm{m}$ ) prior to acid digestion in order to remove particles larger than $11 \mu \mathrm{m}$. Leachate samples were digested with nitric acid, then the digestate passed through MILEXHA $0.45 \mu \mathrm{m}$ diameter filter followed by the US EPA 3005A method [29]. Partially filtered samples containing suspended particles (up to $11 \mu \mathrm{m}$ ) were analyzed for heavy metal content to imitate close to real conditions, as when landfill leachate is analyzed to control compliance with permissible limits. Samples were digested in triplicate and analyzed for the concentrations of $\mathrm{Cd}$ in the final solution using an atomic absorption spectrometer (Perkin Elmer 700). Organic load of the leachate produced at this landfill is 
markedly higher than that of leachate generated in many other countries $[13,30]$; due to the high content of organics such as food wastes. Received municipal solid wastes at Kahrizak landfill is characterized by putrifiable fraction of ca. $68 \%$ and moisture content of $65-70 \%$ that significantly contribute to high organic load of produced leachate. Elevated ratio of biological oxygen demand (BOD)/chemical oxygen demand (COD) for landfill leachate as observed in this study indicates the high concentration of biodegradable organic compounds in leachate, and hence a good potential to be biologically degraded. Some characteristics of the leachate are as follow: $\operatorname{COD}\left(71,245 \mathrm{mg} \mathrm{L}^{-1}\right)$; BOD (32,187 $\left.\mathrm{mg} \mathrm{L}^{-1}\right)$; BOD/ COD (0.45); Total suspended solids $\left(19,800 \mathrm{mg} \mathrm{L}^{-1}\right)$; Total dissolved solids $\left(11,480 \mathrm{mg} \mathrm{L}^{-1}\right) ; \mathrm{NO}_{3}-\mathrm{N}(70 \mathrm{mg}$ $\left.\mathrm{L}^{-1}\right), \mathrm{SO}_{4}\left(1698 \mathrm{mg} \mathrm{L}^{-1}\right)$; electrical conductivity (28.86 $\left.\mathrm{mS} \mathrm{cm}{ }^{-1}\right) ; \mathrm{pH}(5.11)$ and $\mathrm{Pb}\left(1.90 \mathrm{mg} \mathrm{L}^{-1}\right), \mathrm{Mn}(7.78$ $\left.\mathrm{mg} \mathrm{L}^{-1}\right)$ and $\mathrm{Cu}\left(2.52 \mathrm{mg} \mathrm{L}^{-1}\right)$ [28].

\section{BC preparation}

Fresh urban yard trimmings with no pollution background was initially chopped into wood chips of 5-10 $\mathrm{cm}$ length and then oven-dried for $48 \mathrm{~h}$. Yard trimmings can be found abundantly in most places and often used for composting or find their way into urban waste stream. Dried wood chips were placed in open crucibles, then weighted, and covered thoroughly with aluminum foil in order to provide an oxygen-limited environment. $\mathrm{BC}$ derived from the wood chips was produced under the pyrolytic temperature of up to $740{ }^{\circ} \mathrm{C}$ with a temperature gradient of ca. $10^{\circ} \mathrm{C} \mathrm{min}^{-1}$ until the desired temperature of $740 \pm 5^{\circ} \mathrm{C}$ was reached in the muffle furnace under the atmospheric pressure with residence time of $42 \mathrm{~min}$. At the end, samples were kept in the furnace overnight to let them cool down to the room temperature. The produced $\mathrm{BC}$ chips were air-dried over a week, ground using a ceramic mortar and pestle and sieved to gain homogenous crushed wood-derived BC (CWB), with the particle size of 1 to $2 \mathrm{~mm}$. Moreover, some $\mathrm{BC}$ chips were further ground and sieved to 63$75 \mu \mathrm{m}$ diameter to yield fine-graded $\mathrm{BC}$ to be used as pulverized wood-derived $\mathrm{BC}$ (PWB) in the adsorption experiments. Elemental composition of the produced $\mathrm{BC}$ was as follow (dry basis): C (81.5\%), O (11.2\%), H (3.3\%), $\mathrm{N}(0.5 \%), \mathrm{S}(0.1 \%)$ and ash (3.4\%). The produced BC had particle density of $1.5 \mathrm{~g} \mathrm{~cm}^{-3}$. PWB and CWB had bulk densities of 0.93 and $0.69 \mathrm{~g} \mathrm{~cm}^{-3}$, respectively. The $\mathrm{pH}$ of the $\mathrm{BC}$ (9.1) was determined following the method of Singh et al. [31]. BET surface area was measured using a Brunauer-Emmett-Teller Surface Area \& Porosity Analyzer (NOVA 4200e) by nitrogen gas sorption analysis at $77 \mathrm{~K}$. Samples were vacuum degassed prior to analysis, at $300{ }^{\circ} \mathrm{C}$ for 5 to $15 \mathrm{~h}$, based on the required time to reach a stable surface area measurement [32].
BET surface area of the PWB and CWB were determined to be 335 and $281 \mathrm{~m}^{2} \mathrm{~g}^{-1}$, respectively.

\section{Adsorption experiment}

The adsorption process of $\mathrm{Pb}, \mathrm{Mn}$ and $\mathrm{Cu}$ was conducted under the adjusted $\mathrm{pH}$ of 5.1 in order to eliminate the possibility of formation of metal hydroxide precipitates. Solutions were initially adjusted for the desired $\mathrm{pH}$, and then the $\mathrm{BC}$ was added. Values of $\mathrm{pH}$ were measured during the experiments once (for experiments below $600 \mathrm{~min}$ ) or twice (for experiments longer than $600 \mathrm{~min}$ ) for probable $\mathrm{pH}$ adjustment. Precipitation of heavy metal hydroxides between the $\mathrm{pH}$ values of $6.5-7$ was reported for heavy metals [33]. Adsorption of heavy metals onto PWB and CWB was carried out versus time at specified intervals up to $24 \mathrm{~h}$. Actual concentrations of $\mathrm{Pb}, \mathrm{Mn}$ and $\mathrm{Cu}$ ions in leachate samples were considered as the initial concentration, to simulate real conditions. Each adsorption experiment was conducted in triplicate and the mean values were reported. The percentage removal of heavy metals in the solution was calculated using the following equation

$$
R(\%)=\frac{C_{0}-C_{e}}{C_{0}} \times 100
$$

where, $C_{0}$ and $C_{e}$ are, respectively, the initial and final concentrations of $\mathrm{Pb}, \mathrm{Mn}$ and $\mathrm{Cu}$ in leachate samples $\left(\mathrm{mg} \mathrm{L}^{-1}\right)$. Kinetic solutions were stirred on a shaker at constant rate of $120 \mathrm{rpm}$ at room temperature of $24 \pm$ $2{ }^{\circ} \mathrm{C}$ to provide effective interaction of sorbate with sorbent material. At the end of the specified agitation period, obtained mixtures were centrifuged for $15 \mathrm{~min}$ at $6000 \mathrm{rpm}$ to separate liquid and solid phases, filtered by Whatman Paper Filter No. 1 (11 $\mu \mathrm{m}$ pore size) and the filtrates were then analyzed for the heavy metal concentrations. The adsorption isotherms were studied in actual leachate system for $\mathrm{Pb}, \mathrm{Mn}$ and $\mathrm{Cu}$. Certain quantities of PWB and CWB (0.05 to $5 \mathrm{~g}$ ) were separately weighted and added to a $100 \mathrm{~mL}$ fresh landfill leachate at initial $\mathrm{pH}$ of 5.1. The pseudo first-order, pseudo second-order and Elovich models were used to study the kinetics of adsorption of $\mathrm{Pb}, \mathrm{Mn}$ and $\mathrm{Cu}$ onto $\mathrm{BC}$ in landfill leachate and the Langmuir, non-linearized and linearized Freundlich, and Temkin isotherm models were applied to fit the measured data.

\section{Error analysis for the kinetic and isotherm models}

Non-linear regression as a more general technique to estimate parameters of adsorption models can be used even if the model cannot be linearized. However, isotherm and kinetic models are mainly applied in linear form because less difficult calculations are required to find model parameters. It should be noticed that modifying and linearization 
of the original model might violate the theories and assumptions behind the development of a given model that means when parameters are estimated based on linear transformation of a given model it does not necessarily yield best fitting parameters for the nonlinear original model [34]. Error structure of experimental data has been found to be altered when adsorption isotherms transformed into linearized forms. Non-linear regression usually minimizes the error distribution between the experimental and predicted data, unlike linear regression [35]. Therefore, linear determination coefficient $\left(\mathrm{R}^{2}\right)$ should be used to measure the matching degree between experimental and predicted data when linear form of a given adsorption kinetic or isotherm model is applied. Beside linear $R^{2}$, the applicability of the applied models can also be verified through error analysis techniques such as sum of error squares (SSE). The SSE is said to be among the widespread used error functions. It can be written as:

$$
\operatorname{SSE}(\%)=\frac{\sqrt{\sum\left(q_{e(E x p)}-q_{e(C a l)}\right)^{2}}}{N}
$$

where, $q_{\mathrm{e}(\mathrm{Exp})}$ is the adsorption capacity at equilibrium condition obtained from adsorption experiments, $q_{\mathrm{e}(\mathrm{Cal})}$ is the calculated value of adsorption capacity at equilibrium state, and $\mathrm{N}$ is the number of data points [36].

\section{Results and discussion}

\section{Effect of contact time on the adsorption of $\mathrm{Pb}, \mathrm{Mn}$, and} cu onto $B C$ in the leachate

The effect of contact time on the adsorption of $\mathrm{Pb}, \mathrm{Mn}$, and $\mathrm{Cu}$ in landfill leachate is shown in Fig. $1 \mathrm{a}$ and $\mathrm{b}$.

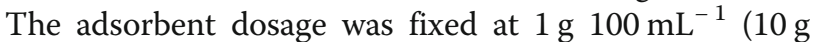
$\mathrm{L}^{-1}$ ) and the $\mathrm{pH}$ value of the fresh leachate was 5.1. The removal efficiency of the heavy metals experienced a drastic initial increase followed by a gradual rise to reach a plateau, which indicates equilibrium condition. Instant adsorption rate of heavy metals onto $\mathrm{BC}$ gradually declined to zero with the equilibrium point of adsorption lay between 150 and 200 and 100-150 min for, respectively, PWB and CWB, suggesting that the contact time of 200 and $150 \mathrm{~min}$ is sufficient to establish dynamic balance. The importance of contact time to provide sufficient contact between adsorbates and adsorbent surface has been emphasized by several authors [35, 37]. It can be inferred from Fig. 1a and $\mathrm{b}$ that the removal of $\mathrm{Pb}$, $\mathrm{Mn}$, and $\mathrm{Cu}$ was greater when PWB was used as adsorbent, compared to CWB. Moreover, longer period of contact time was required for the equilibrium state to be established when $\mathrm{BC}$ with smaller particle size, i.e., PWB was used, implying slower occupation of adsorption sites on the surface of PWB due to the greater specific surface provided by PWB relative to CWB. The highest removal efficiency of $88 \%$ by PWB was obtained for $\mathrm{Pb}$.

As reaction time prolonged, repulsive forces between the metal ions adsorbed to $\mathrm{BC}$ and those in the aqueous phase might be increased. In addition, unoccupied adsorption sites and therefore adsorption efficiency will be quickly declined until the establishment of dynamic balance in the system. The same observation was found for $\mathrm{Ni}$ uptake from aqueous solution by $\mathrm{AC}$ derived from sugar bagasse [37]. From the adsorption diffusion viewpoint, two distinct adsorption stages could be distinguished for the uptake of $\mathrm{Pb}, \mathrm{Mn}$, and $\mathrm{Cu}$ onto $\mathrm{BC}$ in landfill leachate; surface diffusion during which the mass transfer is rapid and physical processes control the adsorption, followed by intra-particle diffusion that is characterized by slow adsorption. Greater adsorption efficiency for heavy metals was observed for all the applied dosages of $\mathrm{BC}$ at initial stages of the experiment, that may be attributed to the higher availability of adsorption sites on $\mathrm{BC}$ surface which are rapidly occupied by the solutes in the leachate. When equilibrium is reached mass transfer from the leachate to the surface of $\mathrm{BC}$ was significantly restricted (Fig. 1a and b), which is consistent with those reported in the literature [13].

\section{Effect of BC dosage on the adsorption of heavy metals in landfill leachate}

$\mathrm{BC}$ dosage varied from 0.05 to $5 \mathrm{~g} 100 \mathrm{~mL}^{-1}$ (0.5 to $50 \mathrm{~g}$ $\mathrm{L}^{-1}$ ) at initial $\mathrm{pH}$ of 5.1 , with the reaction times of 200 and $150 \mathrm{~min}$, respectively, for PWB and CWB. Results indicated that the removal efficiency of the heavy metals was significantly raised by $1.2,1.4$, and 1.6 times, respectively, for $\mathrm{Pb}, \mathrm{Mn}$, and $\mathrm{Cu}$, when $\mathrm{PWB}$ content of the leachate increased from 0.5 to $5 \mathrm{~g} \mathrm{~L}^{-1}$. Obtained results are consistent with the literature, where removal of $\mathrm{Ni}$ from aqueous phase increased by AC dosage [37]. The removal efficiency of $\mathrm{Pb}, \mathrm{Mn}$, and $\mathrm{Cu}$ did not change significantly as $\mathrm{BC}$ content exceeded $2 \mathrm{~g} 100$ $\mathrm{mL}^{-1}$ in leachate. It suggests the optimal dosage of $20 \mathrm{~g}$ $\mathrm{L}^{-1}$ for both PWB and CWB to achieve the highest economical adsorption capacity for the heavy metals. Unsaturated adsorption sites may increase as $\mathrm{BC}$ dosage exceeds the optimum amount. The highest removal efficiency was obtained for $\mathrm{Pb}$ followed by $\mathrm{Mn}$ and $\mathrm{Cu}$ due to addition of PWB (Fig. 1c) and CWB (Fig. 1d).

Removal efficiency of $\mathrm{Mn}$ and $\mathrm{Cu}$ was comparable, with slightly higher elimination for $\mathrm{Mn}$. Amount of $\mathrm{Pb}, \mathrm{Mn}$, and $\mathrm{Cu}$ adsorbed to each gram of $\mathrm{BC}$ reduced with rising adsorbent dosage, likely due to the availability of more adsorption sites on the surface of both PWB and CWB. Optimum AC dosage of $7 \mathrm{~g} 100 \mathrm{~mL}^{-1}$ was found to effectively adsorb $\mathrm{COD}$ and $\mathrm{NH}_{3}$ from landfill leachate [13], which is markedly higher than the optimum dosage of $\mathrm{BC}$ obtained in this study. It might be attributed to the higher 


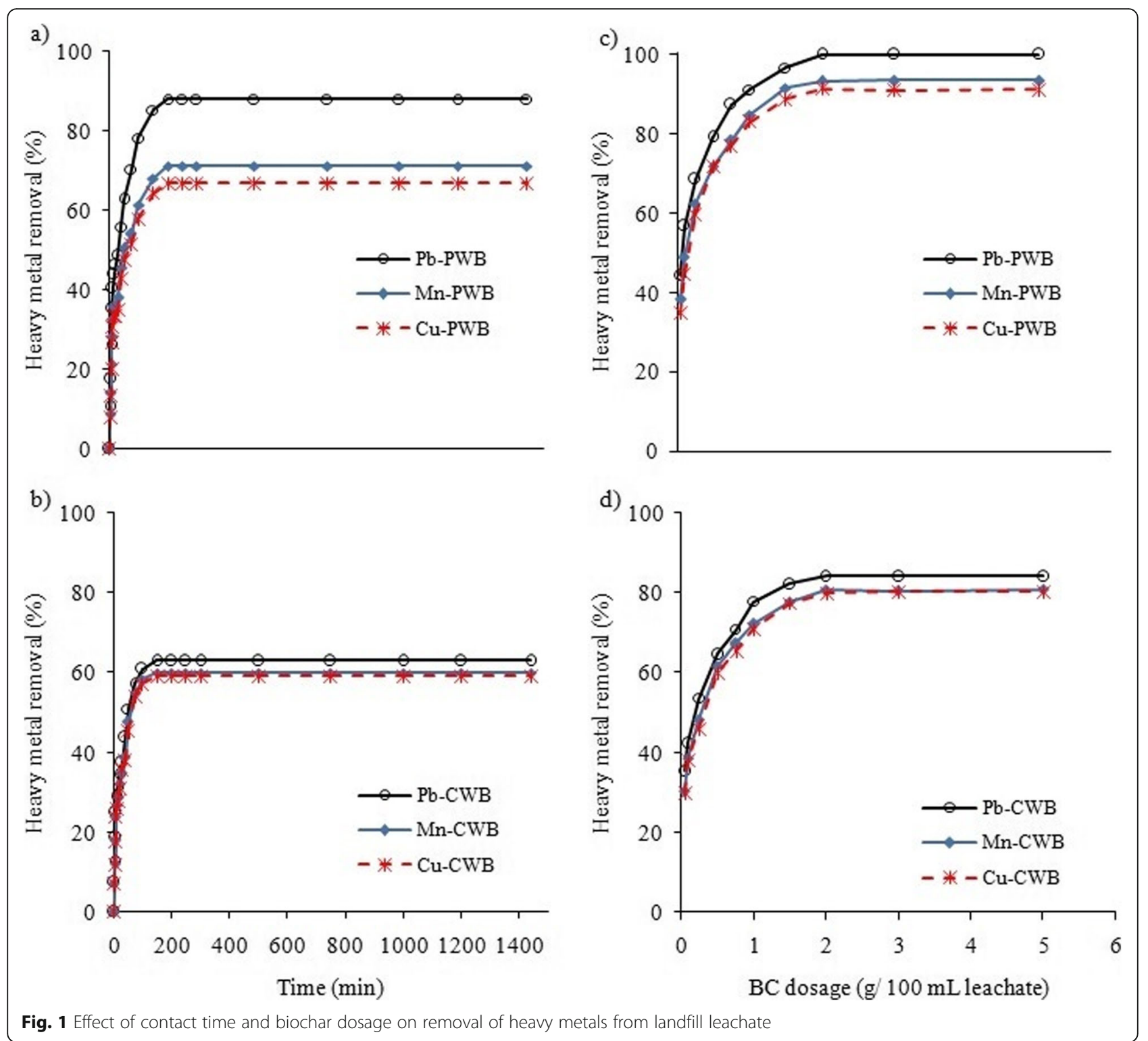

levels of $\mathrm{COD}$ and $\mathrm{NH}_{3}$ in leachate compared to those of heavy metals in this study. $\mathrm{BC}$ dosage may also induce $\mathrm{pH}$ variation, which in turn affects adsorption of adsorbates in aqueous systems by changing the adsorbent surface charge and degree of ionization of adsorbates. Addition of high levels of $\mathrm{BC}$ to fresh leachate may increase $\mathrm{pH}$ and promote the formation of metal hydroxides. However, adverse effect of low $\mathrm{pH}$ on adsorption of $\mathrm{Ni}$ onto $\mathrm{AC}$ has been reported due to competence with hydrogen ions [38]. The influence of $\mathrm{pH}$ on adsorption of heavy metals on various adsorbents has been well documented [14].

\section{Adsorption kinetics}

Batch kinetic experiments were carried out for the adsorption of $\mathrm{Pb}, \mathrm{Mn}$, and $\mathrm{Cu}$ onto $\mathrm{PWB}$ and $\mathrm{CWB}$ in landfill leachate. Lagergren pseudo-first-order model is also one of the most widely used equations to describe adsorption kinetics. However, pseudo-first-order model was not able to well describe adsorption kinetics of heavy metals onto carbonous materials in some studies [5]. In addition, preliminary calculations conducted in this research indicated non-sufficient description of adsorption kinetics of $\mathrm{Pb}, \mathrm{Mn}$ and $\mathrm{Cu}$ onto $\mathrm{PWB}$ and CWB in the landfill leachate (data not shown). Therefore, the kinetics for adsorption of heavy metals onto $\mathrm{BC}$ was simulated using two kinetic models: pseudo second-order and Elovich kinetic models. The experimental effectiveness is controlled by the adsorption kinetics. Adsorption kinetic models are typically used to investigate the adsorption mechanism and the potential rate of the processes such as mass transfer and chemical reactions [13]. 


\section{Pseudo second-order kinetic model}

The non-linear form of pseudo second-order model is represented as follow:

$$
q_{t}=\frac{k_{2 p} q_{e}^{2} t}{1+k_{2 \mathrm{p}} q_{\mathrm{e}} t}
$$

where $k_{2 \mathrm{p}}$ is the second-order adsorption constant ( $\mathrm{g}$ $\left.\mathrm{mg}^{-1} \min ^{-1}\right), q_{\mathrm{e}}$ is the amount of heavy metals adsorbed onto $\mathrm{BC}$ when dynamic balance researched $\left(\mathrm{mg} \mathrm{g}^{-1}\right)$, and $q_{\mathrm{t}}$ is the amount of adsorbate adsorbed onto $\mathrm{BC}$ at any time, $t$. In order to gain the linear form of the pseudo second-order kinetic model the following equation should be solved through integration:

$$
\frac{\mathrm{d} q_{\mathrm{t}}}{\mathrm{d} t}=k_{2 \mathrm{p}}\left(q_{\mathrm{e}}-q_{\mathrm{t}}\right)^{2}
$$

If the boundary conditions of $q_{\mathrm{t}}=0$ to $q_{\mathrm{t}}=q_{\mathrm{t}}$ and $t=0$ to $t=t$ is applied, the model can be written as follows:

$$
\frac{t}{q_{\mathrm{t}}}=\frac{1}{k_{2 \mathrm{p}} q_{\mathrm{e}}^{2}}+\frac{1}{q_{\mathrm{e}}} t
$$

Plots of $t / q_{\mathrm{t}}$ versus $t$ for adsorption of $\mathrm{Pb}$ onto PWB and CWB are illustrated in Fig. 2. Similar graphs could be constructed using the obtained data for $\mathrm{Mn}$ and $\mathrm{Cu}$, with the same trend as $\mathrm{Pb}$. Figure $2 \mathrm{a}$ and $\mathrm{b}$ clearly illustrates higher adsorption capacity of PWB compared to CWB for the heavy metals. The pseudo second-order kinetic constants and the theoretical $q_{e}$ values using the pseudo second-order expression are given in Table 1 for all the studied metals. Very high values of $R^{2}(\geq 0.999)$ were found for the pseudo second-order kinetic model in all applied levels of PWB and CWB indicating an excellent linearity. Results showed an excellent agreement between the experimental data and the calculated adsorption capacity by the pseudo second-order kinetic model which is consistent with the literature, where heavy metals in an aqueous solution were removed by carbon nanotubes [5]. Error analysis indicated that deviation occurred by application of the pseudo secondorder kinetic model is very small for all levels of $\mathrm{BC}$, regardless of the $\mathrm{BC}$ particle size. This supports the chemisorptions theory behind the pseudo second-order kinetic model for the heavy metals/BC system; however, evaluation of variation of adsorption energy using appropriate isotherms such as Temkin model could provide deeper insight into the nature of metal adsorption onto $\mathrm{BC}$. It can be inferred from Table 1 that the adsorption equilibrium rate for the studied heavy metals, regardless of the $\mathrm{BC}$ size, has the following order: $\mathrm{Pb}>\mathrm{Cu}>\mathrm{Mn}$. The applicability of pseudo second-order model to fit the experimental kinetics data was also reported for adsorption of heavy metals onto sewage sludge [24]. Predicted adsorption capacity decreased by increasing dosage of PWB and CWB. The adsorption process is mainly a surface phenomenon and increase in adsorption sites on the surface of an adsorbent at a constant adsorbate level could result in alleviated adsorption intensity.

\section{Elovich kinetic model}

The Elovich adsorption kinetic equation which was initially developed to describe chemisorption kinetics of gas onto solids [39], has recently gained increasing attention to describe kinetics of adsorption of adsorbates in aqueous phase onto adsorbents. The Elovich kinetic model is expressed as follows:
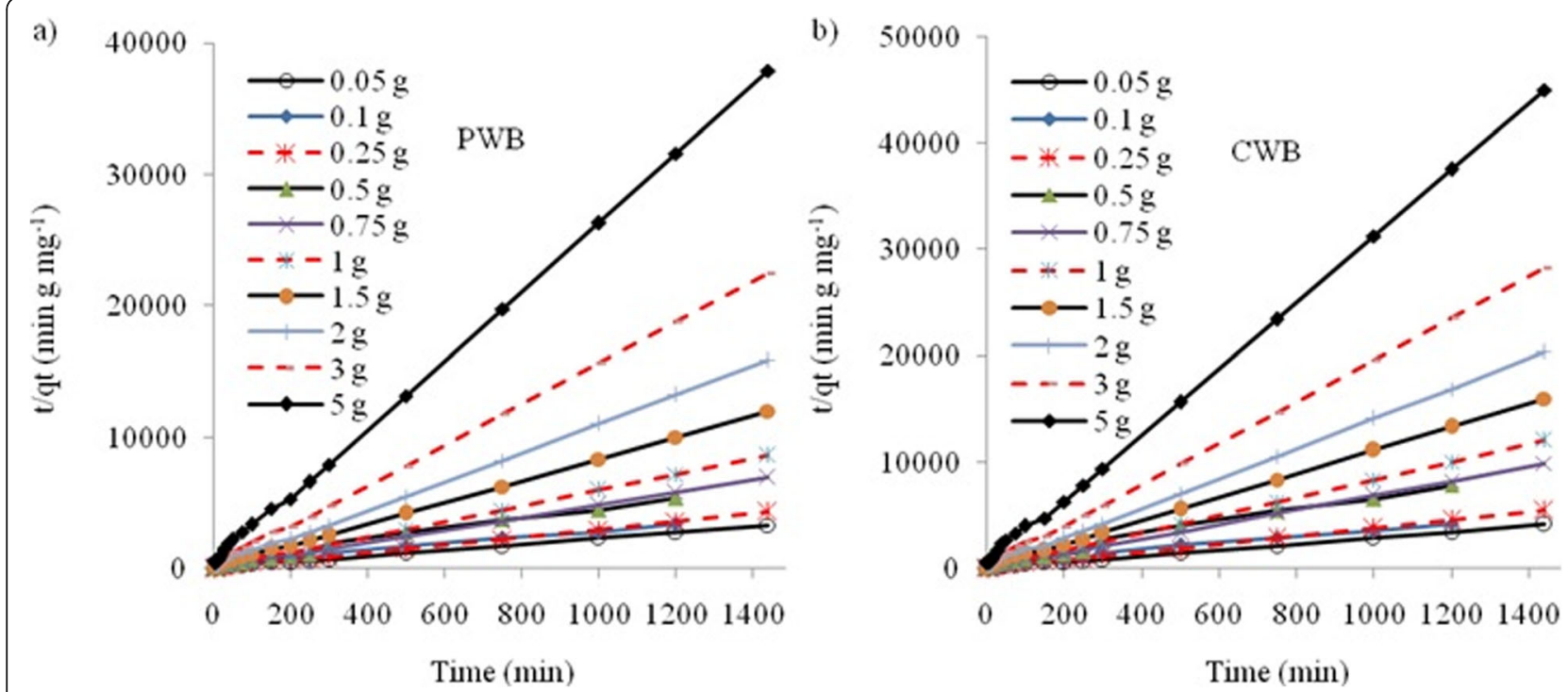

Fig. 2 Linearized pseudo second-order kinetics for adsorption of Pb onto PWB (a) and CWB (b) 
Table 1 Kinetic parameters of the pseudo second-order model for adsorption of heavy metals onto BC in landfill leachate

\begin{tabular}{|c|c|c|c|c|c|c|c|c|c|}
\hline \multirow[t]{2}{*}{ Adsorbate } & \multirow{2}{*}{$\begin{array}{l}\mathrm{BC} \\
\text { dosage }\end{array}$} & \multicolumn{4}{|c|}{ Pseudo second-order kinetic for PWB } & \multicolumn{4}{|c|}{ Pseudo second-order kinetic for CWB } \\
\hline & & $\begin{array}{l}q_{e(c a l .)} \\
\left(\mathrm{mg} \mathrm{g}^{-1}\right)\end{array}$ & $k_{2 p}$ & $R^{2}$ & SSE & $\begin{array}{l}q_{e(c a l .)} \\
\left(\mathrm{mg} \mathrm{g}^{-1}\right)\end{array}$ & $k_{2 p}$ & $\mathrm{R}^{2}$ & SSE \\
\hline \multirow[t]{10}{*}{$\mathrm{Pb}$} & 0.05 & 0.45 & 0.12 & 0.999 & 0.000 & 0.36 & 0.15 & 0.999 & 0.000 \\
\hline & 0.1 & 0.44 & 0.12 & 0.999 & 0.000 & 0.35 & 0.15 & 0.999 & 0.000 \\
\hline & 0.25 & 0.34 & 0.15 & 0.999 & 0.000 & 0.27 & 0.20 & 0.999 & 0.000 \\
\hline & 0.5 & 0.27 & 0.19 & 0.999 & 0.000 & 0.19 & 0.28 & 0.999 & 0.000 \\
\hline & 0.75 & 0.21 & 0.24 & 0.999 & 0.000 & 0.15 & 0.36 & 0.999 & 0.000 \\
\hline & 1 & 0.17 & 0.31 & 0.999 & 0.000 & 0.12 & 0.47 & 0.999 & 0.000 \\
\hline & 1.5 & 0.12 & 0.43 & 0.999 & 0.000 & 0.09 & 0.63 & 0.999 & 0.000 \\
\hline & 2 & 0.09 & 0.56 & 0.999 & 0.000 & 0.07 & 0.79 & 0.999 & 0.000 \\
\hline & 3 & 0.07 & 0.81 & 0.999 & 0.000 & 0.05 & 1.10 & 0.999 & 0.000 \\
\hline & 5 & 0.04 & 1.39 & 0.999 & 0.000 & 0.03 & 1.75 & 0.999 & 0.000 \\
\hline \multirow[t]{10}{*}{$\mathrm{Mn}$} & 0.05 & 1.62 & 0.03 & 0.999 & 0.001 & 1.40 & 0.04 & 0.999 & 0.001 \\
\hline & 0.1 & 1.54 & 0.03 & 0.999 & 0.000 & 1.40 & 0.04 & 0.999 & 0.001 \\
\hline & 0.25 & 1.10 & 0.05 & 0.999 & 0.000 & 0.97 & 0.06 & 0.999 & 0.000 \\
\hline & 0.5 & 0.85 & 0.06 & 0.999 & 0.000 & 0.73 & 0.07 & 0.999 & 0.000 \\
\hline & 0.75 & 0.69 & 0.07 & 0.999 & 0.000 & 0.58 & 0.09 & 0.999 & 0.000 \\
\hline & 1 & 0.56 & 0.09 & 0.999 & 0.000 & 0.47 & 0.12 & 0.999 & 0.000 \\
\hline & 1.5 & 0.43 & 0.12 & 0.999 & 0.000 & 0.36 & 0.16 & 0.999 & 0.000 \\
\hline & 2 & 0.34 & 0.15 & 0.999 & 0.000 & 0.28 & 0.20 & 0.999 & 0.000 \\
\hline & 3 & 0.24 & 0.22 & 0.999 & 0.000 & 0.20 & 0.28 & 0.999 & 0.000 \\
\hline & 5 & 0.15 & 0.35 & 0.999 & 0.000 & 0.13 & 0.45 & 0.999 & 0.000 \\
\hline \multirow[t]{10}{*}{$\mathrm{Cu}$} & 0.05 & 0.40 & 0.13 & 0.999 & 0.000 & 0.46 & 0.11 & 0.999 & 0.000 \\
\hline & 0.1 & 0.39 & 0.13 & 0.999 & 0.000 & 0.43 & 0.12 & 0.999 & 0.000 \\
\hline & 0.25 & 0.33 & 0.16 & 0.999 & 0.000 & 0.32 & 0.17 & 0.999 & 0.000 \\
\hline & 0.5 & 0.26 & 0.20 & 0.999 & 0.000 & 0.24 & 0.23 & 0.999 & 0.000 \\
\hline & 0.75 & 0.22 & 0.24 & 0.999 & 0.000 & 0.18 & 0.29 & 0.999 & 0.000 \\
\hline & 1 & 0.17 & 0.29 & 0.999 & 0.000 & 0.16 & 0.37 & 0.999 & 0.000 \\
\hline & 1.5 & 0.13 & 0.38 & 0.999 & 0.000 & 0.12 & 0.49 & 0.999 & 0.000 \\
\hline & 2 & 0.11 & 0.49 & 0.999 & 0.000 & 0.09 & 0.62 & 0.999 & 0.000 \\
\hline & 3 & 0.08 & 0.70 & 0.999 & 0.000 & 0.07 & 0.87 & 0.999 & 0.000 \\
\hline & 5 & 0.05 & 1.09 & 0.999 & 0.000 & 0.04 & 1.38 & 0.999 & 0.000 \\
\hline
\end{tabular}

$$
\frac{\mathrm{d} q_{\mathrm{t}}}{\mathrm{d} t}=\alpha \exp \left(-\beta q_{\mathrm{t}}\right)
$$

where $\alpha$ is the initial adsorption rate $\left(\mathrm{mg} \mathrm{g}^{-1} \mathrm{~min}^{-1}\right)$ and $\beta$ is defined as desorption constant $\left(\mathrm{g} \mathrm{mg}^{-1}\right)$ during any experiment [36]. Elovich differential equation can be solved assuming $\alpha \beta_{\mathrm{t}}>>1$ and by applying the boundary conditions of $q_{\mathrm{t}}=0$ at $t=0$ and $q_{\mathrm{t}}=q_{\mathrm{t}}$ at $t=t$ [39]. Therefore, the linear form of the Elovich equation can be presented as follows:

$$
q_{\mathrm{t}}=\frac{1}{\beta} \ln (\alpha \beta)+\frac{1}{\beta} \ln t
$$

In order to study the adsorption kinetics using Elovich model a straight line of $q_{\mathrm{t}}$ versus $\ln t$ should be plotted to be able to calculate the model constants of $\alpha$ and $\beta$ from the slope and the intercept of the plot. For instance, $\mathrm{Pb}$ adsorption capacity of $\mathrm{BC}$ predicted by the Elovich kinetic model is shown in Fig. 3. Parameters of the Elovich kinetic model for adsorption of $\mathrm{Pb}, \mathrm{Mn}$ and $\mathrm{Cu}$ onto PWB and CWB are presented in Table 2. Pretty high $\mathrm{R}^{2}$ and low SSE values obtained for the Elovich kinetic model suggesting that adsorption kinetics of the heavy metals onto $\mathrm{BC}$ in landfill leachate can be adequately represented by the Elovich kinetic model. However, higher values of $R^{2}$ and lower values of SSE were found for the pseudo second-order kinetic model compared to the Elovich kinetic expression in this study. Comparison of the kinetic data obtained in this study 
suggests pseudo second-order kinetic expression is the optimum kinetic expression to represent adsorption of $\mathrm{Pb}, \mathrm{Mn}$, and $\mathrm{Cu}$ onto $\mathrm{BC}$ in landfill leachate.

\section{Modeling of adsorption isotherms}

The equilibrium data were modeled using the Langmuir, non-linearized Freundlich, linearized Freundlich and Temkin isotherms in this study to predict adsorption capacity of PWB and CWB for heavy metals in landfill leachate. Experimental data versus the predicted adsorption of $\mathrm{Pb}, \mathrm{Mn}$ and $\mathrm{Cu}$ onto $\mathrm{BC}$ in the leachate using different adsorption isotherms are shown in Fig. 4. Experimental results indicated that $\mathrm{Pb}$ could be adsorbed on $\mathrm{BC}$ to a higher degree than $\mathrm{Mn}$ and $\mathrm{Cu}$. Adsorption of $\mathrm{Mn}$ on $\mathrm{BC}$ was comparable with that of $\mathrm{Cu}$ with slightly higher adsorption for $\mathrm{Mn}$.

\section{Langmuir isotherm}

The Langmuir model which is an empirical isotherm assumes uniform energies of adsorption onto the adsorbent surface with no interaction between adsorbate molecules on adjacent sites. All adsorption is also assumed to occur through the same mechanism to form a layer with a thickness of one molecule on solid surface [25]. Once a site is occupied, no further adsorption can proceed at that site based on the Langmuir isotherm representing the surface saturation condition. Langmuir isotherm has been extensively used to evaluate adsorption capacity of a wide range of contaminants such as heavy metals, organic pollutants and dyes [12]. Langmuir model describes a homogeneous adsorption assuming that all the adsorption sites on the surface of a given adsorbent have equal solute affinity. It is also assumed that adsorption of solute at one site does not affect the adsorption at an adjacent site [40]. Therefore, the maximum adsorption capacity obtained by using the Langmuir isotherm is based on complete monolayer coverage of the surface of adsorbent. All adsorption is assumed to occur through the same mechanism. The non-linear expression of Langmuir isotherm model can be illustrated as follows:

$$
q_{e}=\frac{q_{m} b C_{\mathrm{e}}}{1+b C_{\mathrm{e}}}
$$

where, $b$ is adsorption equilibrium constant $\left(\mathrm{L} \mathrm{mg}^{-1}\right)$ which is related to the apparent energy of adsorption, and $q_{\mathrm{m}}$ is the quantity of adsorbate required to form a single monolayer on unit mass of a given adsorbent $\left(\mathrm{mg} \mathrm{g}^{-1}\right)$.

Values of the constants for different types of linearized Langmuir isotherm are presented in Table 3 for the adsorption of $\mathrm{Pb}, \mathrm{Mn}$ and $\mathrm{Cu}$ onto $\mathrm{BC}$. The applied linearized forms of Langmuir isotherm equation is among the most frequently used linearized forms in the literature [41]. Langmuir isotherm can be further analyzed and the favorable nature of adsorption of adsorbate onto adsorbent can be expressed through determination of the separation factor, $R_{\mathrm{L}}$, which is a dimensionless equilibrium parameter defined by the following equation:

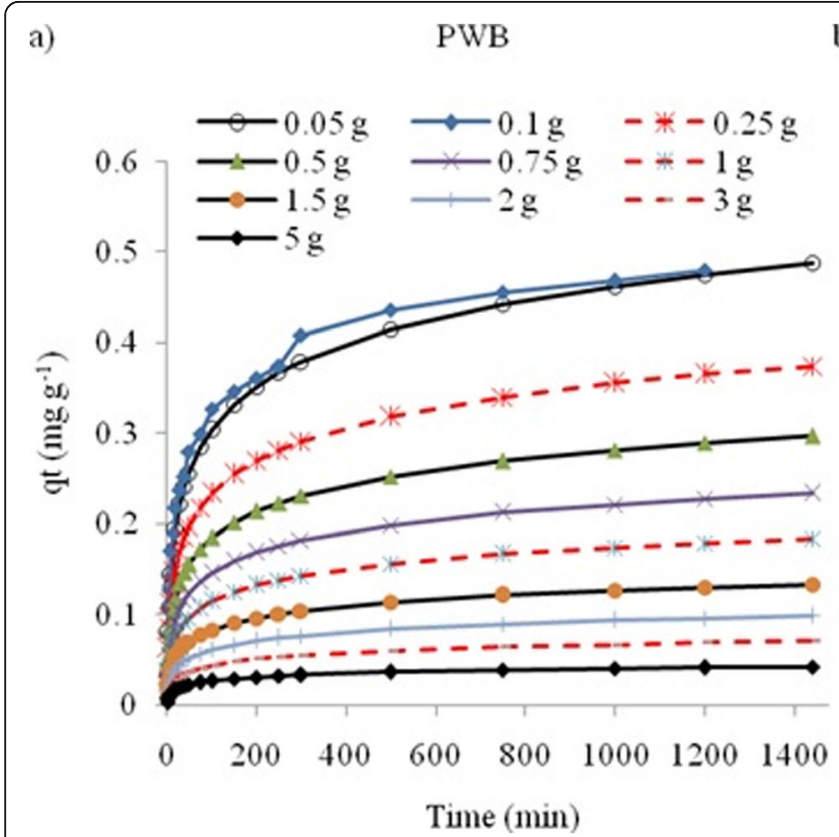

b)

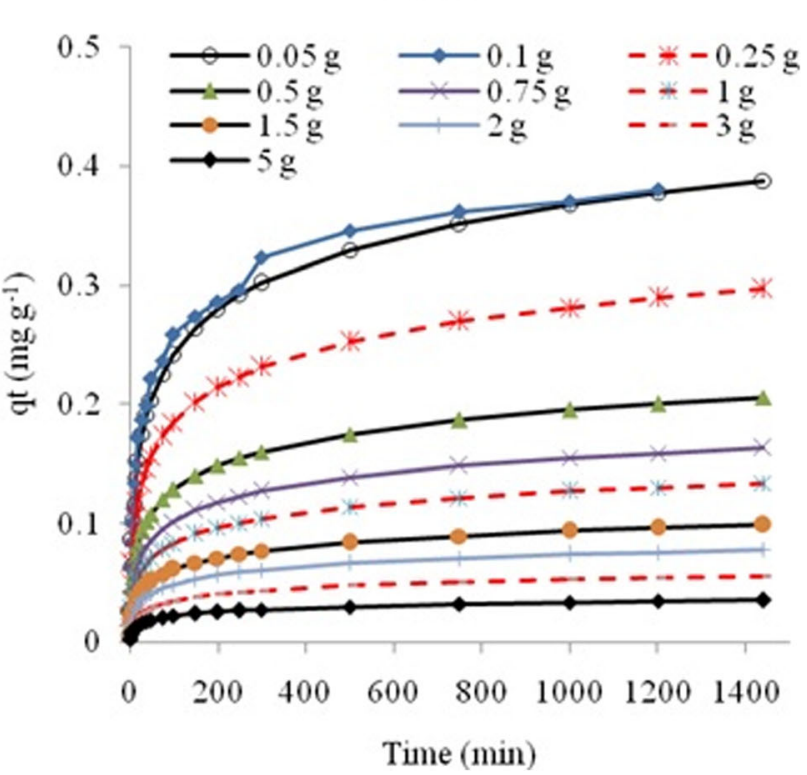

Fig. 3 Determined quantities of adsorption capacity of Pb onto PWB (a) and CWB (b) using the Elovich kinetic model 
Table 2 Kinetic parameters of the Elovich model for adsorption of heavy metals onto BC in landfill leachate

\begin{tabular}{|c|c|c|c|c|c|c|c|c|c|c|c|}
\hline \multirow[t]{2}{*}{ Adsorbate } & \multirow{2}{*}{$\begin{array}{l}\text { Adsorbent } \\
\text { dosage }\end{array}$} & \multirow[b]{2}{*}{$\mathrm{q}_{\mathrm{e}(\text { cal. })}\left(\mathrm{mg} \mathrm{g}^{-1}\right)$} & \multicolumn{4}{|c|}{ Elovich kinetics for PWB } & \multirow[b]{2}{*}{$\mathrm{q}_{\mathrm{e}(\mathrm{cal})}\left(\mathrm{mg} \mathrm{g}^{-1}\right)$} & \multicolumn{4}{|c|}{ Elovich kinetics for CWB } \\
\hline & & & $\beta$ & a & $R^{2}$ & SSE & & $\bar{\beta}$ & $a$ & $R^{2}$ & SSE \\
\hline \multirow[t]{10}{*}{$\mathrm{Pb}$} & 0.05 & 0.49 & 14.5 & 0.056 & 0.953 & 0.002 & 0.39 & 18.2 & 0.044 & 0.955 & 0.001 \\
\hline & 0.1 & 0.48 & 14.7 & 0.055 & 0.952 & 0.002 & 0.38 & 18.5 & 0.043 & 0.956 & 0.001 \\
\hline & 0.25 & 0.37 & 18.9 & 0.043 & 0.948 & 0.002 & 0.30 & 23.8 & 0.034 & 0.955 & 0.001 \\
\hline & 0.5 & 0.30 & 23.8 & 0.034 & 0.948 & 0.001 & 0.21 & 34.5 & 0.024 & 0.955 & 0.000 \\
\hline & 0.75 & 0.23 & 30.3 & 0.027 & 0.949 & 0.001 & 0.16 & 43.5 & 0.019 & 0.955 & 0.000 \\
\hline & 1 & 0.18 & 38.5 & 0.021 & 0.937 & 0.000 & 0.13 & 52.6 & 0.015 & 0.951 & 0.000 \\
\hline & 1.5 & 0.13 & 52.6 & 0.015 & 0.937 & 0.000 & 0.10 & 71.4 & 0.011 & 0.951 & 0.000 \\
\hline & 2 & 0.10 & 71.4 & 0.011 & 0.937 & 0.000 & 0.08 & 90.9 & 0.009 & 0.951 & 0.000 \\
\hline & 3 & 0.07 & 100.0 & 0.008 & 0.939 & 0.000 & 0.06 & 125.0 & 0.006 & 0.951 & 0.000 \\
\hline & 5 & 0.04 & 166.7 & 0.005 & 0.935 & 0.000 & 0.04 & 200.0 & 0.004 & 0.952 & 0.000 \\
\hline \multirow[t]{10}{*}{$\mathrm{Mn}$} & 0.05 & 1.76 & 4.0 & 0.201 & 0.952 & 0.032 & 1.55 & 4.6 & 0.176 & 0.956 & 0.028 \\
\hline & 0.1 & 1.71 & 4.1 & 0.195 & 0.952 & 0.031 & 1.53 & 4.6 & 0.174 & 0.956 & 0.026 \\
\hline & 0.25 & 1.20 & 5.9 & 0.137 & 0.948 & 0.016 & 1.07 & 6.6 & 0.121 & 0.955 & 0.013 \\
\hline & 0.5 & 0.84 & 8.6 & 0.107 & 0.948 & 0.000 & 0.81 & 8.8 & 0.092 & 0.955 & 0.008 \\
\hline & 0.75 & 0.76 & 9.3 & 0.086 & 0.948 & 0.006 & 0.63 & 11.1 & 0.072 & 0.954 & 0.005 \\
\hline & 1 & 0.61 & 11.5 & 0.07 & 0.937 & 0.004 & 0.52 & 13.6 & 0.059 & 0.95 & 0.003 \\
\hline & 1.5 & 0.47 & 15.2 & 0.053 & 0.937 & 0.002 & 0.38 & 18.9 & 0.045 & 0.95 & 0.001 \\
\hline & 2 & 0.37 & 18.9 & 0.043 & 0.937 & 0.002 & 0.31 & 22.8 & 0.035 & 0.95 & 0.001 \\
\hline & 3 & 0.26 & 27.0 & 0.03 & 0.936 & 0.001 & 0.23 & 31.3 & 0.026 & 0.95 & 0.001 \\
\hline & 5 & 0.16 & 43.5 & 0.019 & 0.936 & 0.000 & 0.14 & 50.0 & 0.016 & 0.95 & 0.000 \\
\hline \multirow[t]{10}{*}{$\mathrm{Cu}$} & 0.05 & 0.45 & 15.9 & 0.051 & 0.952 & 0.003 & 0.51 & 13.9 & 0.058 & 0.957 & 0.003 \\
\hline & 0.1 & 0.44 & 16.1 & 0.050 & 0.952 & 0.003 & 0.47 & 15.2 & 0.053 & 0.957 & 0.002 \\
\hline & 0.25 & 0.35 & 20.0 & 0.041 & 0.948 & 0.001 & 0.35 & 20.0 & 0.041 & 0.955 & 0.001 \\
\hline & 0.5 & 0.28 & 25.0 & 0.032 & 0.948 & 0.001 & 0.26 & 27.0 & 0.030 & 0.955 & 0.001 \\
\hline & 0.75 & 0.23 & 30.3 & 0.027 & 0.948 & 0.000 & 0.20 & 35.8 & 0.023 & 0.954 & 0.000 \\
\hline & 1 & 0.19 & 37.0 & 0.022 & 0.937 & 0.000 & 0.17 & 41.7 & 0.019 & 0.955 & 0.000 \\
\hline & 1.5 & 0.14 & 50.0 & 0.016 & 0.937 & 0.000 & 0.13 & 55.6 & 0.014 & 0.955 & 0.000 \\
\hline & 2 & 0.11 & 62.5 & 0.013 & 0.937 & 0.000 & 0.10 & 71.4 & 0.011 & 0.949 & 0.000 \\
\hline & 3 & 0.08 & 90.9 & 0.009 & 0.936 & 0.000 & 0.07 & 100.0 & 0.008 & 0.949 & 0.000 \\
\hline & 5 & 0.05 & 142.9 & 0.006 & 0.937 & 0.000 & 0.04 & 166.7 & 0.005 & 0.948 & 0.000 \\
\hline
\end{tabular}

$$
R_{L}=\frac{1}{1+b C_{0}}
$$

where $\mathrm{b}$ is the Langmuir model constant related to the free energy of adsorption $\left(\mathrm{L} \mathrm{mg}^{-1}\right)$. The $R_{\mathrm{L}}$ indicates the shape of the isotherm. Values of $0<R_{\mathrm{L}}<1$ indicates favorable adsorption, whereas $R_{\mathrm{L}}>1$ represents an unfavorable adsorption. In addition, $R_{\mathrm{L}}=0$ represents irreversible adsorption, while the adsorption is linear if $R_{\mathrm{L}}=1$ [21, 42]. The dimensionless $R_{\mathrm{L}}$ values calculated for adsorption of the heavy metals onto PWB were between zero to one showing favorable adsorption, while the corresponding values for CWB were greater than 1 indicating an unfavorable adsorption (Table 3).

The values of $\mathrm{R}^{2}$ and $R_{\mathrm{L}}$ obtained from Langmuir expression indicate positive evidence that the adsorption of $\mathrm{Pb}, \mathrm{Mn}$, and $\mathrm{Cu}$ onto PWB follows the Langmuir isotherm. The fit of the measured data to the Langmuir model reveals the possibility of sorption of the heavy metals onto PWB through chemisorptions [43]. Negative values obtained for maximum adsorption capacity of $\mathrm{CWB}$ reveals that adsorption of $\mathrm{Pb}, \mathrm{Mn}$ and $\mathrm{Cu}$ onto CWB in the leachate does not follow Langmuir isotherm. In another study, negative values for adsorption capacity of dyes onto AC was obtained [35], which is practically and experimentally impossible. The highest 


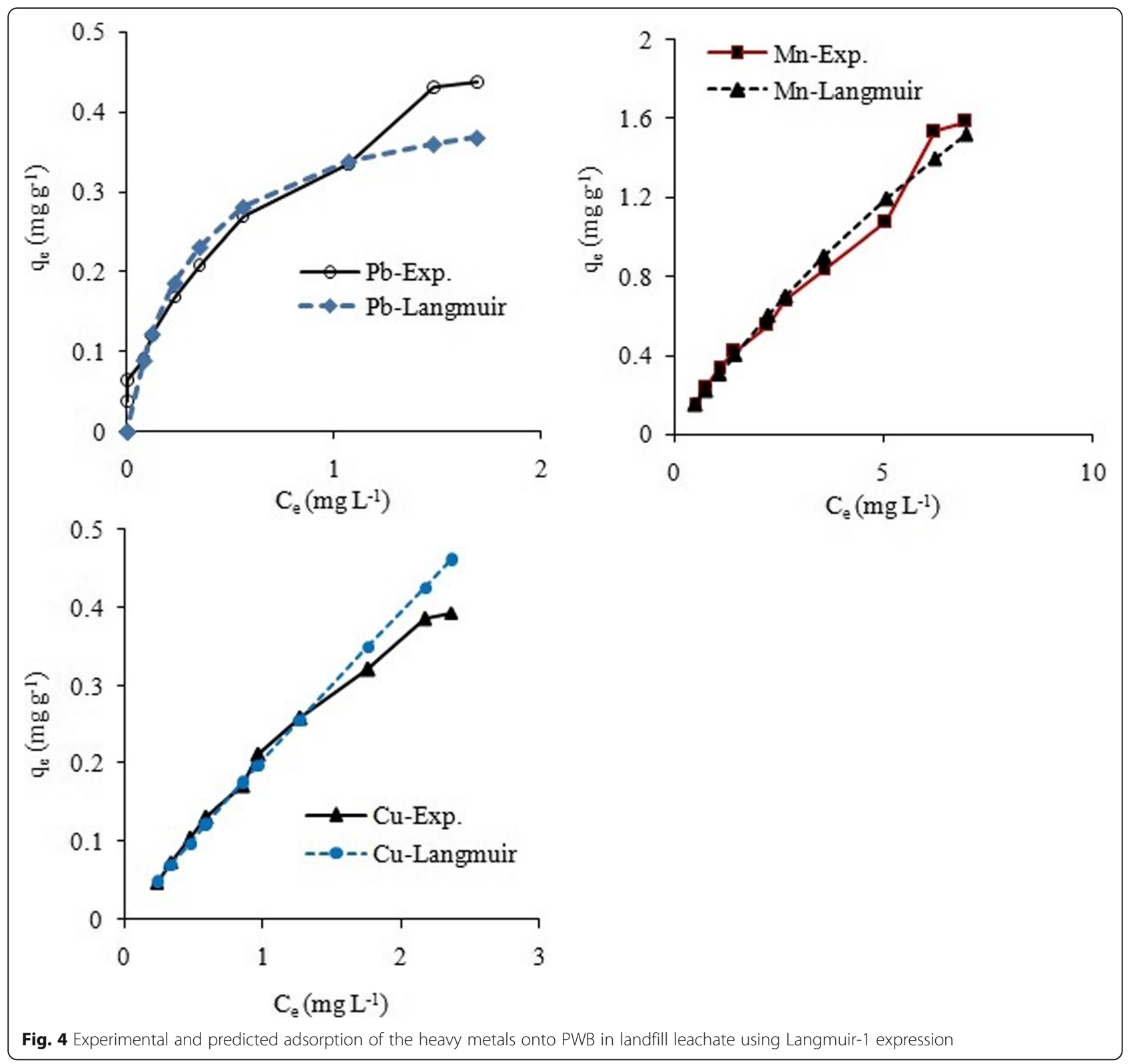

Table 3 Parameters of the Langmuir isotherm for adsorption of $\mathrm{Pb}, \mathrm{Mn}$ and $\mathrm{Cu}$ onto $\mathrm{BC}$ in landfill leachate

\begin{tabular}{|c|c|c|c|c|c|c|}
\hline \multirow{2}{*}{$\begin{array}{l}\text { Langmuir } \\
\text { isotherm- } \\
\text { type } 1\end{array}$} & \multicolumn{2}{|l|}{$\mathrm{Pb}$} & \multicolumn{2}{|l|}{$\mathrm{Mn}$} & \multicolumn{2}{|l|}{$\mathrm{Cu}$} \\
\hline & PWB & CWB & PWB & CWB & PWB & CWB \\
\hline $\mathrm{q}_{\mathrm{m}}\left(\mathrm{mg} \mathrm{g}^{-1}\right)$ & 0.44 & -0.22 & 5.60 & -0.65 & 5.90 & -0.21 \\
\hline$b\left(\mathrm{~L} \mathrm{mg}^{-1}\right)$ & 3.22 & -0.46 & 0.05 & -0.12 & 0.04 & -0.37 \\
\hline$R^{2}$ & 0.985 & 0.965 & 0.993 & 0.944 & 0.994 & 0.944 \\
\hline $\mathrm{R}_{\mathrm{L}}$ & 0.14 & 8.86 & 0.70 & 23.05 & 0.92 & 18.28 \\
\hline SSE & 0.016 & 0.364 & 0.045 & 9.593 & 0.008 & 0.842 \\
\hline
\end{tabular}

value of the Langmuir constant $b, 3.2 \mathrm{~L} \mathrm{mg}^{-1}$, was obtained for $\mathrm{Pb}$ adsorption onto PWB (Table 3) exhibiting greater affinity of $\mathrm{Pb}$ for the surface of $\mathrm{PWB}$ compared to $\mathrm{Mn}$ and $\mathrm{Cu}$ in landfill leachate. It seems that the monolayer adsorption capacity of $\mathrm{Pb}$ onto $\mathrm{PWB}$ provides a better fit to the experimental data compared to $\mathrm{Mn}$ and $\mathrm{Cu}$. Experimental results showed that adsorbed amounts of the heavy metals on $\mathrm{BC}$ were clearly increased with rising adsorbent dosage. Figure 4 compares the simulated isotherm curves and measured data for adsorption of $\mathrm{Pb}, \mathrm{Mn}$ and $\mathrm{Cu}$ onto $\mathrm{BC}$ based on Langmuir expression. Results indicated that Langmuir isotherm is unable to describe the equilibrium data perfectly in most cases. 


\section{Linearized and non-linearized Freundlich isotherms}

The Freundlich isotherm has been widely applied to characterize the adsorption of organic and inorganic pollutants using various adsorbents [44]. Freundlich isotherm constants found through plotting $\ln q_{e}$ vs $\ln C_{e}$ are given in Table 4. The ratio of the amount of adsorbate adsorbed onto a given mass of adsorbent to the adsorbate concentration in the solution using the Freundlich model is represented by the following equation:

$$
q_{e}=K_{F} C_{e^{\frac{1}{n}}}
$$

where, $K_{\mathrm{f}}$ is the Freundlich constant representing the relative adsorption intensity of the adsorbent related to the bonding energy, and $n$ is the heterogeneity factor indicating the deviation from linearity of adsorption which is commonly known as Freundlich coefficient. Linearized form of the Freundlich isotherm can be used to evaluate the adsorption data and determine the Freundlich model constants as follows:

$$
\ln q_{e}=\ln K_{F}+\frac{1}{n} \ln C_{e}
$$

The corresponding coefficients of correlation for Freundlich model were found to be high for adsorption of $\mathrm{Pb}, \mathrm{Mn}$, and $\mathrm{Cu}$ onto PWB and CWB ( $\geq 0.99)$ indicating a good linearity; however, the values of Freundlich coefficient, $n$, did not fall within the favorable range for CWB. Favorability of the Freundlich isotherm is generally indicated by the magnitude of the exponent $n$. The values of $\mathrm{n}$ ranging from 2 to 10 is stated to represent a good fit, values ranging from 1 to 2 indicates relatively difficult adsorption, and less than 1 shows poor adsorption characteristics [45]. Acceptable adsorption characterized by values of $n$ between 1 and 10 has also been reported in the literature $[21,46]$. The highest value of the Freundlich coefficient was obtained for adsorption of $\mathrm{Pb}$ onto PWB $(n=2.0)$ (Table 4). Higher values of $K_{\mathrm{f}}$ were found for adsorption of the heavy metals onto PWB indicating the greater relative adsorption capacity of PWB compared to CWB to eliminate $\mathrm{Pb}, \mathrm{Mn}$, and $\mathrm{Cu}$ from the landfill leachate. Results show that linearized Freundlich and Langmuir models could not adequately describe adsorption of $\mathrm{Pb}, \mathrm{Mn}$, and $\mathrm{Cu}$ onto $\mathrm{CWB}$ in landfill leachate. In order to find the Freundlich maximum adsorption capacity, $q_{m}$, it is necessary to keep the initial concentration of adsorbate constant and use the variable dosage of adsorbent; that means $\ln q_{m}$ is the extrapolated value of $\ln q$ for $C=C_{0}$. Thus, the Freundlich maximum adsorption capacity can be described as follows:

$$
q_{m}=K_{F}\left(C_{0}\right)^{\frac{1}{n}}
$$

where, $q_{m}$ is the Freundlich maximum adsorption capacity $\left(\mathrm{mg} \mathrm{g}^{-1}\right)$. The calculated maximum adsorption capacity of $\mathrm{PWB}$ for $\mathrm{Pb}, \mathrm{Mn}$, and $\mathrm{Cu}$ using the Freundlich isotherm were greater than the corresponding values for CWB, respectively, by a factor of $2.3,5.3$, and 1.4. Comparing the maximum adsorption capacity produced by application of the Freundlich and Langmuir-1 models reveals that predicted $q_{\max }$ using the Freundlich isotherm is markedly lower than the corresponding values obtained by the Langmuir-1 expression for PWB.

It can be inferred from the Fig. 5a, b and $\mathrm{c}$ that the predicted adsorption capacity of PWB and CWB using the linearized Freundlich isotherm is drastically underestimated for $\mathrm{Pb}, \mathrm{Mn}$ and $\mathrm{Cu}$. Experimental data on adsorption of the heavy metals onto $\mathrm{BC}$ in landfill leachate also suggest higher performance of PWB than CWB. Adsorbent particle size may considerably affect removal of target contaminants from aqueous solutions. Higher effectiveness of PWB compared to CWB in sorption of

\begin{tabular}{|c|c|c|c|c|c|c|c|}
\hline \multirow[t]{2}{*}{ Isotherm } & \multirow[t]{2}{*}{ Parameters } & \multicolumn{2}{|l|}{$\mathrm{Pb}$} & \multicolumn{2}{|l|}{$\mathrm{Mn}$} & \multicolumn{2}{|l|}{$\mathrm{Cu}$} \\
\hline & & PWB & CWB & PWB & CWB & PWB & CWB \\
\hline \multirow[t]{5}{*}{ Linearized Freundlich Isotherm } & $\mathrm{K}_{\mathrm{F}}$ & 0.09 & 0.02 & 0.06 & 0.00 & 0.02 & 0.01 \\
\hline & $n$ & 1.99 & 0.74 & 1.14 & 0.67 & 1.11 & 0.67 \\
\hline & $R^{2}$ & 0.994 & 0.994 & 0.992 & 0.990 & 0.991 & 0.991 \\
\hline & $q_{\max }$ & 0.12 & 0.05 & 0.34 & 0.06 & 0.06 & 0.04 \\
\hline & SSE & 0.374 & 0.312 & 5.086 & 5.536 & 0.446 & 0.528 \\
\hline \multirow[t]{5}{*}{ Non-linearized Freundlich Isotherm } & $\mathrm{K}_{\mathrm{F}}$ & 0.34 & 0.19 & 0.28 & 0.91 & 0.20 & 0.14 \\
\hline & $n$ & 2.03 & 0.81 & 1.11 & 0.72 & 1.22 & 0.71 \\
\hline & $R^{2}$ & 0.967 & 0.990 & 0.988 & 0.989 & 0.993 & 0.998 \\
\hline & $q_{\max }$ & 0.47 & 0.42 & 1.75 & 1.65 & 0.43 & 0.53 \\
\hline & SSE & 0.0064 & 0.0012 & 0.0281 & 0.0216 & 0.0009 & 0.0004 \\
\hline
\end{tabular}
heavy metals in landfill leachate can also be attributed to

Table 4 Linearized and non-linearized Freundlich isotherm constants for adsorption of Pb, Mn and Cu onto BC 

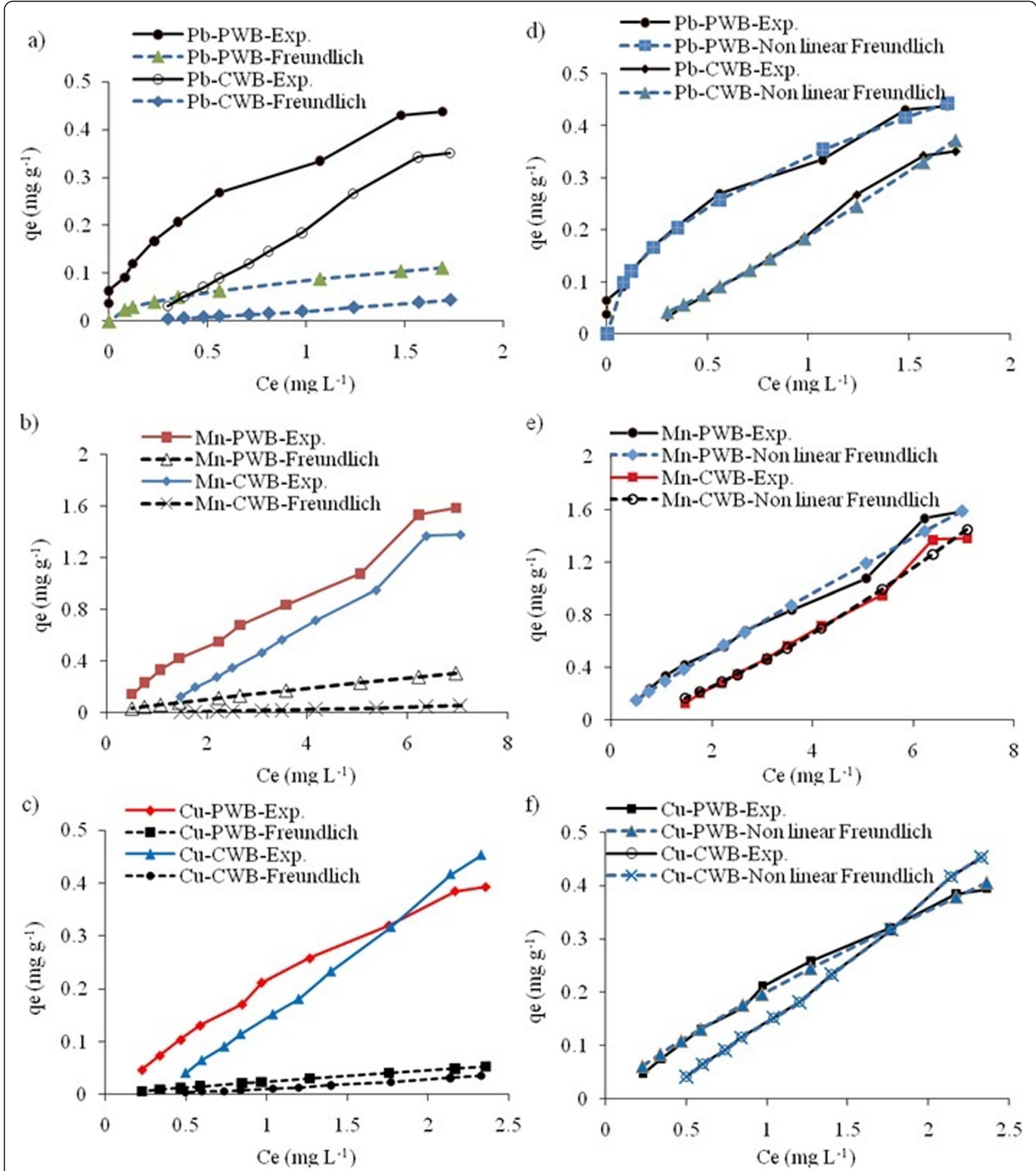

Fig. 5 Experimental and predicted adsorption of the heavy metals in leachate onto PWB and CWB using linearized and non-linearized Freundlich equations

the increased internal surface area with decreasing $\mathrm{BC}$ particle size [47]. Smaller particle size provides high capability of adsorption as a result of transfer of heavy metals through shorter pathways inside the adsorbent particle pores [48]. In a previous study, $\mathrm{Cr}$ removal from an aqueous solution declined from 70 to $14 \%$, when the Eucalyptus camaldulensis particle size increased from 0.063 to $2 \mathrm{~mm}$ [49], which is consistent with our findings. Higher BET surface area obtained for PWD compared to $\mathrm{CWB}$ is another reason for higher adsorption 
efficiency and capacity of PWB, as suggested in the literature [50].

Error analysis also indicates high values of SSE for linearized Freundlich isotherm. The SSE values found for the Freundlich model are significantly higher than the obtained values for the Langmuir model. Overally, results indicated no adequate agreement between the predicted and measured adsorption data, implying the lack of validity of the linearized Freundlich isotherm to model the adsorption of the heavy metals onto $\mathrm{BC}$ in the leachate. Both linear and non-linear fitting of the experimental data to the Freundlich model yield high $R^{2}$ in most cases but the error analysis presented a great difference between linear and non-linear fitting. The value of SSE calculated for non-linear fitting was much lower than that obtained for linear fitting, as it could also be realized by comparing experimental and modeled data presented in Fig. 5d, e and f. Results indicate that nonlinear fitting of the measured data to the Freundlich isotherm could provide significantly more robust prediction compared to the linear fitting. However, the obtained values for the constant $n$ was less than 1 when CWB was used as an adsorbent both for linear and non-linear fitting of data indicating unfavorable adsorption of $\mathrm{Pb}$, $\mathrm{Mn}$, and $\mathrm{Cu}$ onto $\mathrm{CWB}$. Results indicated much higher values of $q_{m}$ when non-linearized regression was applied. In other words, linearization of the Freundlich isotherm caused underestimation of $q_{m}$, while fitting the measured data to non-linearized form of the Freundlich model depicted greater affinity between the experimental and predicted data. Application of non-linear Freundlich isotherm produced more valid data with significantly higher values of $R^{2}$ as well as much smaller SSE. Overally, results indicated that linearization of the Freundlich isotherm to fit the experimental data may generate higher errors and significantly deviate the predicted adsorption capacity of a given adsorbent from the experimental data.

\section{Temkin isotherm}

Temkin isotherm equation contains a factor that reflects the adsorbent-adsorbate interactions. The nonlinear form of Tempkin isotherm is represented by the following equation:

$$
q_{\mathrm{e}}=\frac{R T}{b_{\mathrm{T}}} \ln \left(K_{\mathrm{T}} C_{\mathrm{e}}\right)
$$

where, $T$ is the absolute temperature in Kelvin (K), $R$ is the universal gas constant, $8.314 \mathrm{~J} \mathrm{~mol}^{-1} \mathrm{~K}^{-1}, b_{\mathrm{T}}$ is the constant related to the heat of adsorption indicating the variation of adsorption energy $\left(\mathrm{J} \mathrm{mol}^{-1}\right)$, and $K_{\mathrm{T}}$ is the Temkin equilibrium binding constant $\left(\mathrm{L} \mathrm{g}^{-1}\right)$ corresponding to the maximum binding energy. The dimensionless term $(R T) / b_{\mathrm{T}}$ can be substituted by $B_{\mathrm{T}}$, thus Temkin isotherm equation can be linearized as given by the following equation:

$$
q_{\mathrm{e}}=B_{\mathrm{T}} \ln K_{\mathrm{T}}+B_{\mathrm{T}} \ln C_{\mathrm{e}}
$$

The obtained parameters of Temkin model are given in Table 5. Values of $\mathrm{R}^{2}$ found using the linear transformation of the Temkin equation, were comparable to the non-linearized Freundlich model. The variation of adsorption energy, $b_{\mathrm{T}}$, was positive for all the studied heavy metals implying that the adsorption of $\mathrm{Pb}, \mathrm{Mn}$ and $\mathrm{Cu}$ onto $\mathrm{BC}$ is an exothermic reaction $\left(22 \mathrm{~kJ} \mathrm{~mol}^{-1}\right)$. Salam reported that the physical adsorption is characterized by adsorption energy in the range of $5-40 \mathrm{~kJ} \mathrm{~mol}^{-1}$ [5]. Physiosorption may occur as a result of weak forces of Van der Waals between the adsorbates and adsorbents [12]. Higher amounts of variation of energy obtained using the Temkin isotherm for adsorption of $\mathrm{Pb}$, $\mathrm{Mn}$, and $\mathrm{Cu}$ onto PWB relative to those obtained for CWB indicates greater capacity of PWB to adsorb heavy metals in landfill leachate. It should be noticed that the Temkin isotherm does not provide any estimation of the maximum adsorption capacity of a given adsorbent. In spite of the non-linear Langmuir equation, if the equilibrium concentration is increased, the adsorption capacity of the original Temkin equation, $q_{e}$, does not converge to any limiting value. Figure 6 indicates that the predicted equilibrium curves using Temkin model are very close to those obtained experimentally; however, deviation of the predicted adsorption using the Temkin model slightly increased when lower dosage of $\mathrm{BC}$ was applied. Error analysis indicates smaller values of the SSE relative to the Langmuir-1 and linear Freundlich isotherms; however, the non-linear Freundlich model exhibited the lowest values of SSE for adsorption of $\mathrm{Pb}$, $\mathrm{Mn}$ and $\mathrm{Cu}$ onto $\mathrm{BC}$ in this study. Based on the obtained results it seems that Temkin model can adequately describe the adsorption of the heavy metals onto PWB and $\mathrm{CWB}$ in the leachate. Adsorption of $\mathrm{Pb}, \mathrm{Mn}$ and $\mathrm{Cu}$ onto $\mathrm{BC}$ in landfill leachate was adequately represented by the applied isotherm models, except the linear Freundlich model implying that adsorption of heavy metals onto $\mathrm{BC}$ may be controlled by surface diffusion and pore

Table 5 Temkin isotherm parameters for adsorption of $\mathrm{Pb}, \mathrm{Mn}$

\begin{tabular}{|c|c|c|c|c|c|c|}
\hline \multirow{2}{*}{$\begin{array}{l}\text { Temkin } \\
\text { isotherm } \\
\text { parameters }\end{array}$} & \multicolumn{2}{|l|}{$\mathrm{Pb}$} & \multicolumn{2}{|l|}{$\mathrm{Mn}$} & \multicolumn{2}{|l|}{$\mathrm{Cu}$} \\
\hline & PWB & CWB & PWB & CWB & PWB & CWB \\
\hline $\mathrm{b}_{\mathrm{T}}$ & 0.11 & 0.19 & 0.54 & 0.82 & 0.15 & 0.27 \\
\hline $\mathrm{K}_{\mathrm{T}}$ & 22.3 & 3.2 & 1.8 & 0.7 & 4.6 & 2.0 \\
\hline$R^{2}$ & 0.964 & 0.935 & 0.889 & 0.930 & 0.958 & 0.938 \\
\hline SSE & 0.004 & 0.008 & 0.262 & 0.131 & 0.006 & 0.018 \\
\hline
\end{tabular}
and $\mathrm{Cu}$ onto $\mathrm{BC}$ in the leachate 


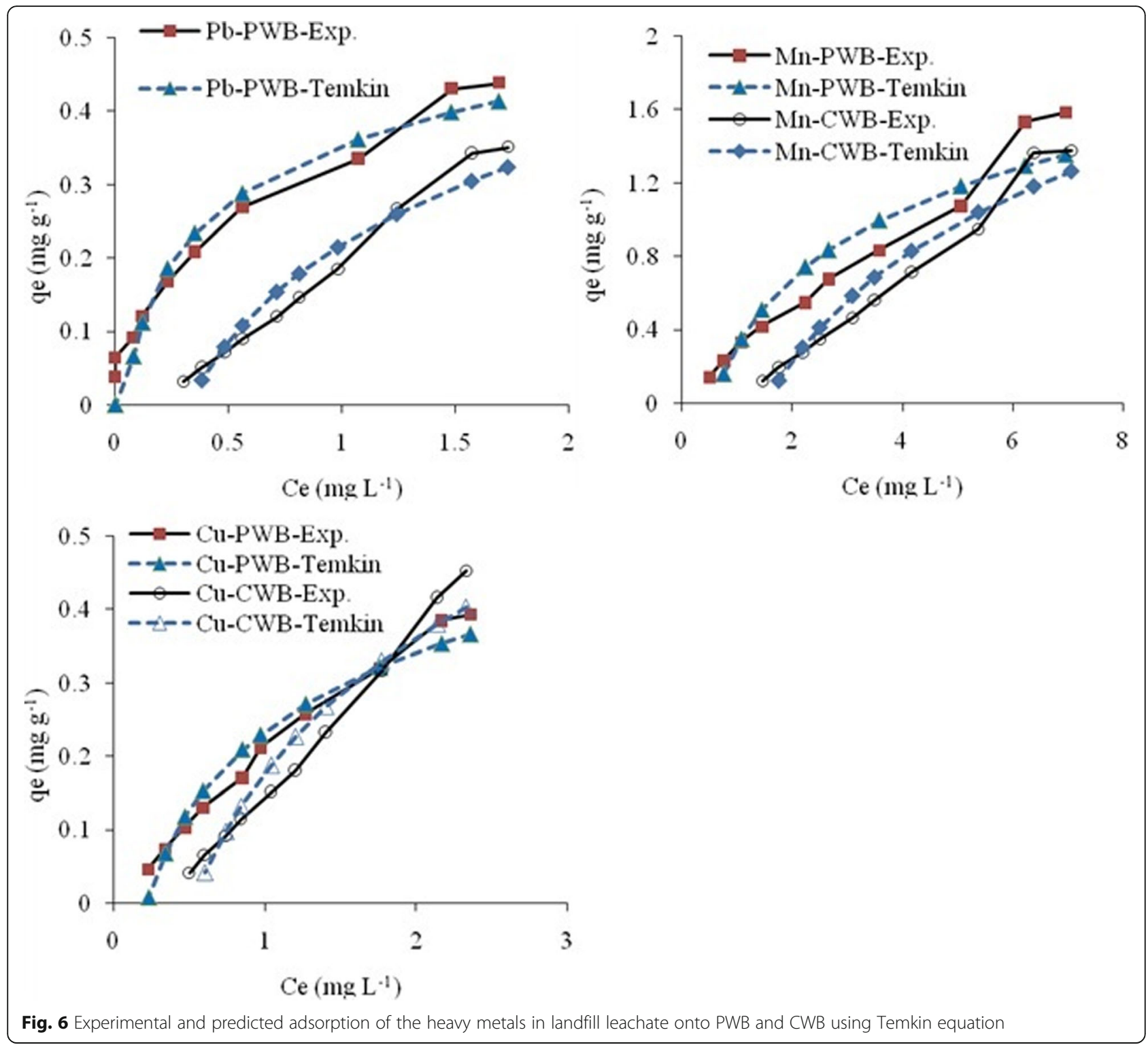

diffusion simultaneously as well as adsorption at an active preoccupied site. Overally, results indicated promising removal of the heavy metals from landfill leachate using $\mathrm{BC}$, which could be well described by nonlinearized Freundlich and Temkin models.

\section{Conclusions}

The present study aimed to assess the capability of $\mathrm{BC}$ in removal of $\mathrm{Pb}, \mathrm{Mn}$ and $\mathrm{Cu}$ from landfill leachate and model the adsorption kinetics and isotherms of the heavy metals onto BC. Results indicated that the woodderived $\mathrm{BC}$ is an effective adsorbent for the removal of $\mathrm{Pb}, \mathrm{Mn}$ and $\mathrm{Cu}$ from landfill leachate. The adsorption affinity of $\mathrm{PWB}$ for $\mathrm{Pb}, \mathrm{Mn}$, and $\mathrm{Cu}$ was greater than CWB in all treatments. The contact times of 200 and 150 min were sufficient to reach adsorption equilibrium condition, respectively for PWB and CWB. The removal efficiency of the heavy metals only slightly enhanced as $\mathrm{BC}$ dosage exceeded $20 \mathrm{~g} \mathrm{~L}^{-1}$. PWB showed the highest experimental adsorption intensity of $1.58 \mathrm{mg} \mathrm{g}^{-1}$ for the removal of $\mathrm{Mn}$ from the landfill leachate. Beside BC particle size, other properties such as structural and pore space volume of $\mathrm{BC}$ may also affect adsorption behavior of heavy metals in aqueous solutions, which is suggested to be further investigated in future studies. The pseudo second-order kinetic model precisely represented the adsorption kinetic data for $\mathrm{BC}$ suggesting the chemisorptions of $\mathrm{Cd}$ onto $\mathrm{BC}$ particles. Calculated $q_{e}$ using the Elovich kinetics model also agreed well with the experimental $q_{e}$. Two distinct adsorption stages for the adsorption of the heavy metals onto $\mathrm{BC}$ in the leachate was clearly observed; first the migration of metals from the 
leachate system to the external surface of $\mathrm{BC}$ during which the mass transfer is very rapid and physical processes control the adsorption, followed by the prolonged intra-particle diffusion characterized by slow adsorption. The non-linear Freundlich isotherm best describes the equilibrium adsorption data, followed by the Temkin isotherm. Linearized Freundlich model could only moderately describe adsorption of the heavy metals onto PWB, while it was not able to represent the adsorption by CWB. Linearization method for the Langmuir isotherm also affects the error structure suggesting that the linearization of non-linear isotherm models may violate the theory behind an isotherm and alter error distribution. It is recommended to use wood-derived $\mathrm{BC}$ as an effective adsorbent to remove heavy metals from landfill leachate.

\section{Acknowledgments}

The authors would like to thank the University of Tehran for the support. The first author would also like to sincerely thank the Labor of Applied Geosciences, University of Tübingen, Germany, for the skilled laboratory support.

\section{Authors' contributions}

Ali Daryabeigi Zand (ADZ) was responsible for developing the theory and idea, carrying out the experiments, performing and verifying the analytic calculations and numerical simulations, and writing the manuscript. Maryam Rabiee Abyaneh (MRA) was responsible for carrying out the experiments, performing the analytic calculations and numerical simulations, and writing the manuscript. The authors read and approved the final manuscript.

\section{Funding}

This work was supported by University of Tehran.

\section{Availability of data and materials}

All data generated or analyzed during this study are included within the article.

\section{Competing interests}

The authors declare they have no competing interests.

Received: 29 April 2020 Accepted: 19 August 2020

Published online: 09 September 2020

\section{References}

1. Phan TN, Van Truong TT, Ha NB, Nguyen PD, Bui XT, Dang BT, et al. High rate nitrogen removal by ANAMMOX internal circulation reactor (IC) for old landfill leachate treatment. Bioresour Technol 2017;234:281-8.

2. Poblete R, Oller I, Maldonado MI, Luna Y, Cortes E. Cost estimation of COD and color removal from landfill leachate using combined coffee-waste based activated carbon with advanced oxidation processes. J Environ Chem Eng 2017;5:114-21.

3. Xu J, Long YY, Shen DS, Feng HJ, Chen T. Optimization of Fenton treatment process for degradation of refractory organics in pre-coagulated leachate membrane concentrates. J Hazard Mater 2017;323:674-80.

4. Dan A, Oka M, Fujii Y, Soda S, Ishigaki T, Machimura T, et al. Removal of heavy metals from synthetic landfill leachate in lab-scale vertical flow constructed wetlands. Sci Total Environ 2017:584-5:742-50.

5. Salam MA. Removal of heavy metal ions from aqueous solutions with multiwalled carbon nanotubes: kinetic and thermodynamic studies. Int J Environ Sci Te 2013:10:677-88.

6. Erabee IK, Ahsan A, Jose B, Aziz MMA, Ng AWM, Idrus S, et al. Adsorptive treatment of landfill leachate using activated carbon modified with three different methods. KSCE J Civ Eng 2018;22:1083-95.

7. Foo KY, Hameed BH. An overview of landfill leachate treatment via activated carbon adsorption process. J Hazard Mater 2009;171:54-60.
8. Beesley L, Moreno-Jimenez E, Gomez-Eyles JL, Harris E, Robinson B, Sizmur T. A review of biochars' potential role in the remediation, revegetation and restoration of contaminated soils. Environ Pollut 2011;159:3269-82.

9. Issabayeva G, Aroua MK, Sulaiman NM. Study on palm shell activated carbon adsorption capacity to remove copper ions from aqueous solutions. Desalination. 2010;262:94-8.

10. Wong S, Ngadi N, Inuwa IM, Hassan O. Recent advances in applications of activated carbon from biowaste for wastewater treatment: a short review. J Clean Prod 2018;175:361-75.

11. Soco E,Kalembkiewicz J. Adsorption of nickel(II) and copper(II) ions from aqueous solution by coal fly ash. J Environ Chem Eng 2013;1:581-8.

12. Itodo $\mathrm{AU}$, Itodo HU, Gafar MK. Estimation of specific surface area using Langmuir isotherm method. J Appl Sci Environ Manag 2011;14:141-5.

13. Shehzad A, Bashir MJK, Sethupathi S, Lim JW. An insight into the remediation of highly contaminated landfill leachate using sea mango based activated bio-char: optimization, isothermal and kinetic studies. Desalin Water Treat 2016;57:22244-57.

14. Kavitha D, Namasivayam C. Experimental and kinetic studies on methylene blue adsorption by coir pith carbon. Bioresour Technol 2007:98:14-21.

15. Regazzoni AE. Adsorption kinetics at solid/aqueous solution interfaces: on the boundaries of the pseudo-second order rate equation. Colloid Surface A 2020;585:124093.

16. Tofighy MA, Mohammadi T. Adsorption of divalent heavy metal ions from water using carbon nanotube sheets. J Hazard Mater 2011;185:140-7.

17. Largitte L, Pasquier R. A review of the kinetics adsorption models and their application to the adsorption of lead by an activated carbon. Chem Eng Res Des 2016:109:495-504.

18. Pandiarajan A, Kamaraj R, Vasudevan S, Vasudevan S. OPAC (orange peel activated carbon) derived from waste orange peel for the adsorption of chlorophenoxyacetic acid herbicides from water: adsorption isotherm, kinetic modelling and thermodynamic studies. Bioresour Technol 2018;261: 329-41.

19. Malwade K, Lataye D, Mhaisalkar V, Kurwadkar S, Ramirez D. Adsorption of hexavalent chromium onto activated carbon derived from Leucaena leucocephala waste sawdust: kinetics, equilibrium and thermodynamics. Int J Environ Sci Te 2016:13:2107-16.

20. Balarak D, Mostafapour FK, Azarpira H, Joghataei A. Langmuir, Freundlich, Temkin and Dubinin-Radushkevich isotherms studies of equilibrium sorption of ampicilin unto montmorillonite nanoparticles. Brit J Pharm Res 2017;20:1-9.

21. Igwe JC, Abia AA. Adsorption isotherm studies of $\mathrm{Cd}$ (II), Pb (II) and $\mathrm{Zn}$ (II) ions bioremediation from aqueous solution using unmodified and EDTAmodified maize cob. Eclet Quím 2007;32:33-42.

22. Qambrani NA, Rahman MM, Won S, Shim S, Ra C. Biochar properties and eco-friendly applications for climate change mitigation, waste management, and wastewater treatment: a review. Renew SustEnerg Rev 2017;79:255-73.

23. de Caprariis B, De Filippis P, Hernandez AD, Petrucci E, Petrullo A, Scarsella $M$, et al. Pyrolysis wastewater treatment by adsorption on biochars produced by poplar biomass. J Environ Manage 2017;197:231-8.

24. Agrafioti E, Kalderis D, Diamadopoulos E. Arsenic and chromium removal from water using biochars derived from rice husk, organic solid wastes and sewage sludge. J Environ Manage 2014;133:309-14.

25. Chen BL, Yuan MX. Enhanced sorption of polycyclic aromatic hydrocarbons by soil amended with biochar. J Soil Sediment 2011;11:62-71.

26. Marchal G, Smith KEC, Rein A, Winding A, de Jonge LW, Trapp S, et al. Impact of activated carbon, biochar and compost on the desorption and mineralization of phenanthrene in soil. Environ Pollut 2013;181:200-10.

27. Pazoki M, Abdoli MA, Karbassi AR, Mehrdadi N, Yaghmaeian K. Attenuation of municipal landfill leachate through land treatment. J Environ Health Sci 2014;12:12.

28. Baird RB, Eaton AD, Rice EW, editors. Standard methods for the examination of water and wastewater. 23rd ed. Washington, DC: American Public Health Association; 2017

29. USEPA. SW-846 test method 3005A: acid digestion of waters for total recoverable or dissolved metals for analysis by flame atomic absorption (FLAA) or inductively coupled plasma (ICP) spectroscopy. Washington, DC: US Environmental Protection Agency; 1992.

30. Xue Q, Li JS, Wang P, Liu L, Li ZZ. Removal of heavy metals from landfill leachate using municipal solid waste incineration fly ash as adsorbent. Clean-Soil Air Water 2014;42:1626-31.

31. Singh B, Dolk MM, Shen $\mathrm{QH}$, Camps-Arbestain M. Biochar $\mathrm{pH}$, electrical conductivity and liming potential. In: Singh B, Camps-Arbestain M, Lehmann 
J, editors. Biochar: a guide to analytical methods. Clayton South: Csiro Publishing; 2017. p. 23-38.

32. Qiu YP, Zheng ZZ, Zhou ZL, Sheng GD. Effectiveness and mechanisms of dye adsorption on a straw-based biochar. Bioresour Technol 2009;100:534851.

33. Bogusz A, Oleszczuk P, Dobrowolski R. Adsorption and desorption of heavy metals by the sewage sludge and biochar-amended soil. Environ Geochem Hlth 2019:41:1663-74.

34. Nagy B, Manzatu C, Maicaneanu A, Indolean C, Lucian BT, Majdik C. Linear and nonlinear regression analysis for heavy metals removal using Agaricusbisporusmacrofungus. Arab J Chem 2017;10:S3569-79.

35. Kumar KV. Linear and non-linear regression analysis for the sorption kinetics of methylene blue onto activated carbon. J Hazard Mater 2006;137:1538-44.

36. Idris S, lyaka YA, Ndamitso MM, Mohammed EB, Umar MT. Evaluation of kinetic models of copper and lead uptake from dye wastewater by activated pride of barbados shell. Am J Chem 2011;1:47-51.

37. Krishnan KA, Sreejalekshmi KG, Baiju RS. Nickel(II) adsorption onto biomass based activated carbon obtained from sugarcane bagasse pith. Bioresour Technol 2011;102:10239-47.

38. Tagavifar M, Jang SH, Sharma H, Wang D, Chang LY, Mohanty K, et al. Effect of pH on adsorption of anionic surfactants on limestone: experimental study and surface complexation modeling. Colloid Surface A 2018;538:54958.

39. Ngah WSW, Kamari A, Koay Y. Equilibrium and kinetics studies of adsorption of copper(II) on chitosan and chitosan/PVA beads. Int J Biol Macromol 2004; 34:155-61.

40. Langmuir I. The adsorption of gases on plane surfaces of glass, mica and platinum. J Am Chem Soc 1918:40:1361-403.

41. Hamdaoui $\mathrm{O}$, Naffrechoux E. Modeling of adsorption isotherms of phenol and chlorophenols onto granular activated carbon - Part II. Models with more than two parameters. J Hazard Mater 2007;147:401-11.

42. Hall KR, Eagleton LC, Acrivos A, Vermeulen T. Pore- and solid-diffusion kinetics in fixed-bed adsorption under constant-pattern conditions. Ind Eng Chem Fund 1966;5:212-23.

43. Kizito S, Wu SB, Kirui WK, Lei M, Lu QM, Bah H, et al. Evaluation of slow pyrolyzed wood and rice husks biochar for adsorption of ammonium nitrogen from piggery manure anaerobic digestate slurry. Sci Total Environ 2015;505:102-12.

44. El-Aila HJ, Elsousy KM, Hartany KA. Kinetics, equilibrium, and isotherm of the adsorption of cyanide by MDFSD. Arab J Chem 2016;9:S198-203.

45. Elbana TA, Selim HM, Akrami N, Newman A, Shaheen SM, Rinklebe J. Freundlich sorption parameters for cadmium, copper, nickel, lead, and zinc for different soils: influence of kinetics. Geoderma. 2018;324:80-8.

46. Stromer BS, Woodbury B, Williams CF. Tylosin sorption to diatomaceous earth described by Langmuir isotherm and Freundlich isotherm models. Chemosphere. 2018;193:912-20.

47. Al-Anber MA. Thermodynamics approach in the adsorption of heavy metals. In: Moreno Pirajan JC, editor. Thermodynamics - interaction studies - solids, liquids and gases. London: IntechOpen; 2011.

48. Al-Anber MA. Removal of high-level $\mathrm{Fe}^{3+}$ from aqueous solution using natural inorganic materials: bentonite (NB) and quartz (NQ). Desalination. 2010;250:885-91.

49. Gebretsadik H, Gebrekidan A, Demlie L. Removal of heavy metals from aqueous solutions using Eucalyptus Camaldulensis: an alternate low cost adsorbent. Cogent Chem 2020;6:1720892.

50. Akpomie KG, Dawodu FA, Adebowale KO. Mechanism on the sorption of heavy metals from binary-solution by a low cost montmorillonite and its desorption potential. Alex Eng J 2015;54:757-67.

\section{Publisher's Note}

Springer Nature remains neutral with regard to jurisdictional claims in published maps and institutional affiliations.

Ready to submit your research? Choose BMC and benefit from:

- fast, convenient online submission

- thorough peer review by experienced researchers in your field

- rapid publication on acceptance

- support for research data, including large and complex data types

- gold Open Access which fosters wider collaboration and increased citations

- maximum visibility for your research: over $100 \mathrm{M}$ website views per year

At BMC, research is always in progress.

Learn more biomedcentral.com/submissions 